\title{
Five CAPABILITIES OF DESIGN ENGINEERS: TOWARDS UNDERSTANDING THE TRANSDISCIPLINARY COMPETENCIES
}

\author{
Minha R. Ha and Aleksander Czekanski \\ Mechanical Engineering, Lassonde School of Engineering, York University \\ minhareo@yorku.ca
}

\begin{abstract}
Today there is a growing emphasis on responsible engineering design, which commits its practice to sustainable, ethical, equitable outcomes in the broader societal level. For engineers involved in the design, development, and implementation of existing and emerging technologies, such responsibility requires skillfulness on multiple fronts, for example: facilitating the integration of cross-disciplinary expertise and knowledge; translating a detailed problem understanding from its sociocultural settings into technical requirements; and negotiating requirements and priorities with key internal and external stakeholders. In order to understand how design engineers access, acquire, and effectively utilize knowledge outside their technical disciplines, especially pertaining to the human and social contexts of the design problem and designer practice, an online survey and in-depth interviews were conducted with professional engineers. The paper discusses potentially important design engineer capabilities that engineering educators should consider. We welcome discussions and feedback on our ongoing work.
\end{abstract}

Keywords: engineering design, transdisciplinary competencies, socio-technical integration

\section{INTRODUCTION}

Transdisciplinary knowledge capability of designers, termed Type-2 knowledge by Nowotny [1], has been a well-discussed topic of interest by design researchers [2][5]. However, there is a lack of a coherent theoretical framework, practical strategies or empirical data on transdisciplinarity for design engineers, possibly due to the level of sheer complexity in working with interacting i.e. human, social, and technical systems that require different disciplines and paradigms to analyze. The difficulty with interpreting complex systems arises from "an observer's lack of familiarity or ability to understand the system" [3, p.8]. A robust characterization and empirical data on the designer's transdisciplinary capability are needed.
Recognizing that multi-, inter-, and trans-disciplinarity were becoming important to responsible design and governance of technologies, we set out to define first the potentially transdisciplinary nature of engineering design practice, comparing the literature with the results of informational interviews we had with engineering design instructors in our school.

This resulted in a multidimensional understanding of a design engineer's work: Engineering Design (ED) is a value-driven process of collective inquiry (including collective intelligence management), during which design engineers must identify and interpret user needs, and translate them to functional requirements, to operational requirements, to schematics for manufacturing purposes, etc. [6]. This translation work is inherently 'risky,' since achieving the e.g. operational requirements does not guarantee solving the original problem. Such translation of information from one design domain and stage to another, can sometimes produce 'boundary objects' [7] that capture new knowledge being synthesized as multiple epistemologies or disciplines come into meaningful engagement. One area of translation that is particularly difficult is from the sociocultural domain to the technophysical domain [4]. This became our focus of study: socio-technical knowledge integration and translation. Five abilities then were proposed as important sites of socio-technical knowledge integration (STKI) in ED practice:

Collective inquiry - Design engineers actively pose questions and acquire different types of knowledge relevant to the design problem at hand. They learn from teams, clients and stakeholders with expertise outside a design engineer's field of training. Design engineers also contribute to the organization's accumulation of relevant knowledge.

Contextualization - Design engineers must be able to perceive and investigate the interaction between the systems (e.g. ecological, institutional, information) that embed or shape the design problem and solution. Contextual knowledge includes the historical and cultural 
aspect of how multiple systems and their interactions have come to the present state.

Knowledge translation - Design engineers regularly translate information and knowledge to make aligned connection between job functions (e.g. designer, technician, sales), between requirements (e.g. design specifications, manufacturing requirements, operation requirements), between domains (e.g. multiple systems interaction), between long-term impact outcomes and immediate technical performance metrics.

Reflective practice (original term by Donald Schön) Design engineers can make value-based choices within the design process (e.g. material, evaluation criteria), as well as about the projects they work in. They need time to assess and improve their practice, even as they develop their own philosophical understanding of design, workplace, and relevant problem phenomena.

Negotiation - Design engineers often do not have the ultimate decision making authority, but offer perspectives, key evidence and rationale needed. They must articulate effective value propositions for the work or choices they are proposing, to be heard and to secure resources. They often take on consultative roles with clients, developing a shared understanding and agreement about the design goals and priorities. Negotiation is also an important skillset for upholding standards of safety, quality and ethics.

This framework was used to generate questions then posed to engineers with design practice experience in the industry. This paper presents results that focus on the following questions: How do engineers effectively acquire and integrate socio-technical knowledge, as it bears upon the design work? What are the key action/interaction processes, and outcomes? What are the mediating factors?

\section{METHODS}

\subsection{Online Survey}

An online survey titled, Socio-Technical Knowledge Integration in Engineering Design, was developed on SurveyMonkey and began data collection in January 2019 (https://www.surveymonkey.com/r/STKI2019). The survey link was posted on the first author's LinkedIn page, and forwarded to known contacts to invite participation or forwarding. Engineers with any years of experience in engineering design were invited. After removing duplicate responses, 11 of 13 unique individuals' responses were moved forward for analysis based on their completion of the survey ( 22 open-ended questions; 2 drop-down menu items; 32 Likert-scale items; 14 Yes/No questions; 1 ranking response item). All survey participants completed $>70 \%$ of the survey, except
F3 and M5 (see Appendix A), who completed less than $15 \%$ of the survey.

\subsection{In-depth Interviews}

Through existing personal network and referrals, engineers were invited to audio-recorded in-depth interviews with the first author. In addition to predesigned interview questions, the five designer capabilities framework and preliminary survey results were presented for interviewees' comments. Each interview lasted $1.5-2$ hours. This paper draws supporting data from 2 of 10 engineers who have been interviewed as of date. The selected two interviewees are nicknamed Cube and Yellow: both have mechanical engineering background, with similar experience level (15-20 years in industry), male and between the ages of 35-44. Yellow has a leadership role in sales and business development, while Cube leads the operations in his company.

\subsection{Data Analysis}

Survey responses were reviewed for patterns in the responses (e.g. rating, key themes). Interview transcripts were first coded by paragraphs, summarizing key ideas by using in vivo concept codes. Relevant paragraphs were selected for more detailed analysis of the concept relations (e.g. association, causal), even as the concepts from across paragraphs and interviews were being organized into categories. When defining the relationship between concept categories, the action/interaction process framework from grounded theory methods is adopted [8]. The framework helps identify where further data collection is required, to test hypotheses and reach a 'theoretical saturation' of evidence and counterevidence that help us select among multiple possible theoretical explanations of the data. Re-iteration of data collection and analysis is a common feature of grounded theory studies.

This paper focuses on understanding and revising the initial designer capability framework, based on participant perspectives on their experiences, meanings, observations and example practices. Emerging results were critiqued and discussed amongst the research team (whose training, skillset, and unique positioning provide insider and outsider perspectives to the engineers' realities), as well as presented in seminars, poster presentations and the subsequent interviews to solicit engineers' feedback.

\section{FINDINGS AND DISCUSSION}

As part of the survey, engineers (Appendix A) were asked to indicate how strongly they agree with 15 statements that relate to their design experience ( $\mathrm{SA}=$ strongly agree; $\mathrm{A}=$ agree; $\mathrm{N}=$ neither agree nor disagree; $\mathrm{D}=$ disagree; $\mathrm{SA}=$ strongly disagree). The results 
are below. Relevant statements for each category (3.1 3.4) are presented first, followed by graphs showing response rates (Fig. 1-5).

\subsection{Collective Inquiry}

a. "I regularly work with knowledge outside my discipline."

b. "The success of engineering design depends heavily on integrating knowledge and expertise across multiple disciplines within engineering."

c. "The success of engineering design depends heavily on integrating knowledge and expertise across multiple epistemologies and paradigms (disciplines across the natural sciences, social sciences, engineering, humanities, business, education, law, etc.)."

d. "It is difficult to access all required knowledge and information pertaining to the design problem."

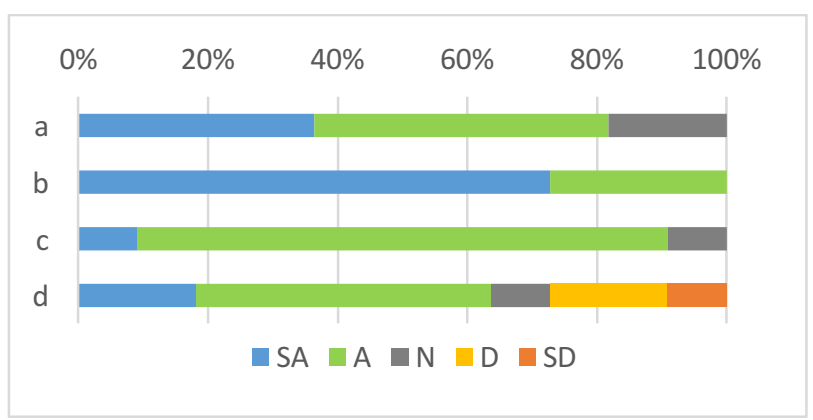

Fig. 1. Survey Responses on Collective Inquiry.

Survey respondents generally agreed that multi- and interdisciplinary knowledge was important to their project success $[b, c]$. However, there is some indication that accessing the right knowledge and information can be difficult [d]. Even before translation, information access is a critical issue for proper problem formulation and translation to evaluation.

When asked about obtaining knowledge needed for the design work, Yellow and Cube commonly described the direct, in-person interaction they (and their design engineers) have with the holders of such knowledge. This includes engaging with the different engineering disciplines (multi-disciplinary), with sales and marketing teams (inter-disciplinary), and with the clients:

[...] So within engineering it's very open in the sense that we train each other. And if someone has a question, you just turn around and ask your neighbour, the person next cubicle for help, and some of mentoring. That way it also happens across departments. Sales and marketing is also working on those projects. [...] So the hardware and software together. [...] we have [...] the customer interaction with the sales. Engineers can go, can be embedded into those diverse teams going to events, going to work shows, conferences. [...] (Yellow, 8)

Being on the same projects and in physical proximity, meaningful engagement of peer learning was encouraged. Engineers were also being sent to meet directly with their (potential) clients. Cube emphasizes the skills of listening, questioning, and establishing a deeper understanding of the problem, as important to design success:

[...]. Listen $80 \%$ of the time speak $20 \%$ of the time. You can't learn if you're speaking. It's better to hear out somebody's problem. [...] One reason, you can't possibly be solving their problem if you don't know exactly what their problem is. Second reason, it's just that's how you establish trust with somebody. They have to believe they've been heard and you know where they've been heard. [...] Salespeople that will go in and just [talk and tell] "this is how you got to do things"- 99 times out of a hundred are rejected.

Whereas people who come in and say, "Hey, what's the nature of your problem? [...] Do you have this problem?" and guide them along those questions and establish some sort of a rapport [...] THEN You give your ideas and then those ideas are received much

better than they would be otherwise if you just walked in and threw'em on the table. (Cube, 17)

Cube recognizes that design success requires accurate problem understanding, as well as adoption by actual users. The learning process includes skillful listening, asking good questions to create a shared understanding of the problem, as well as building rapport by valuing user input before offering value to the users. The interdepartmental engagements also help establish the problem understanding, as well as a contextualized view of single tasks as part of full solutions. Yellow stresses the importance of such understanding, created through key interactions that his organization fostered or hindered. organizational factors to foster key interactions:

The company started like that. Organically, Very sort of flat and open and, and have engineers [...] have different contributions in different sort of roles like marketing, sales. And then we went into more like a silo organization for efficiency's sake [...] for a few years. [...] We reverted, haha. We changed our mind like other companies do, I hear. So what didn't work is the lack of communication between departments. So we could have some efficiencies within departments, by really focusing on some technical details, but what we were losing too much by doing that in terms of interaction with the other sides of the company.

So the big picture was getting lost [...] Most people were less and less aware of what was happening 
outside of the sort of area of their expertise. [...] It also affects the quality of what you produce ultimately [...] Internally we were feeling some deficiencies in terms of being able to find a full solution. So an example would be, the designers and developers would do some work, with some conceptions and some sort of vague idea of what the end result should be. And then when sort of the market representative people saw that [...] that wasn't meeting the expectations of what the product should be or should do, and then it was going back to the design board. And so some of the work had to be [re]done, so inefficiencies that way [...] It just makes more sense if we can integrate all those unique user needs right from the first time you design something. It's just faster and more efficient and less painful. [That] also affects not only the bottom line, but it affects the company. Like the overall satisfaction with people's goals, and their contribution, satisfaction. (Yellow, 810)

Compromising key interactions for efficiency purposes can actually compromise critical understandings formed through key interactions, which can actually delay and cause unnecessary repetition in the design efforts. The design work inherently requires ongoing feedback and inquiry, and cannot be simply compartmentalized into isolated tasks.

Also important to note is the effect of design work experience on the engineers' morale. Being able to contribute value, and to have their work count, are important aspects to support through workplace practices.

\subsection{Contextualization}

e. "Success as a design engineer requires knowledgeability in the human- and socialsystems."

f. "I have confidence in creating win-win solutions for the organization, the clients, the public, and the environment."

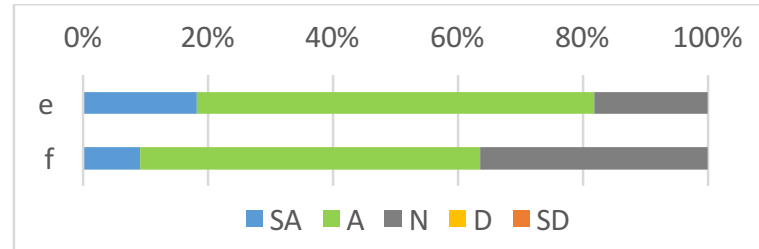

Fig. 2. Survey Responses on Contextualization.

There are human and social systems that embed the design problem, as well as design practice. Viewing the context as systems is of great use to clarifying the role of technology, navigating the influences to its development and adoption, as well as understanding the technology impact on broader society and environment. Cube, who views the staff as his internal clients, explains how understanding the client's and technology contexts may be key to articulating the value offered by the design solution [f]:

[When] there's no immediate need [...] sometimes timing is of the essence and you know, moving quickly and beating the competition to something is important. So it's all of those factors that we intuit and, and from my perspective, I tried to speak often with, you know, the directors of the other departments to $s$ to understand their priorities. And then from an operations perspective, we prioritize around them. You know, we say, okay, if that's what's important to you, then that's what we'll focus on first. You know, so that we get it done in time for it to actually have value [...] If you need a tool [and] it's not available for two years, that ship [opportunity] might have sailed already. (Cube, 5)

The changing context of user needs (e.g. competition, trends) determines the priorities for design work. Such contextualized knowledge, can serve as the first immediate target output for inquiry. This output would affect problem definition, theoretical understanding of the user practice, design choices and value proposition.

\subsection{Knowledge Translation}

g. "It is difficult to transform user needs into technical requirements (system, operational, element function, production, etc.).",

h. "Having met the design criteria does NOT necessarily mean that the user needs have been met.".

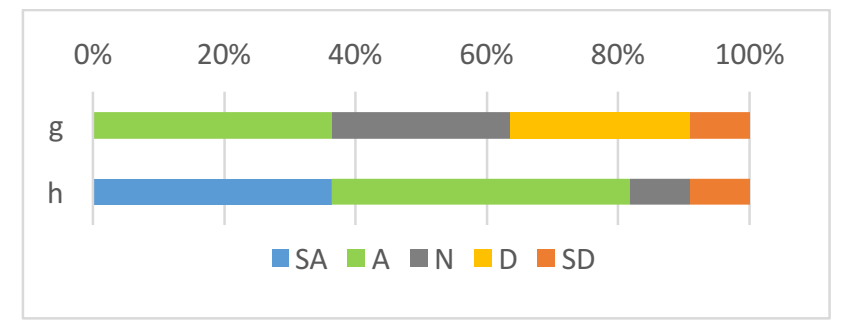

Fig. 3. Survey Responses on Knowledge Translation.

Although there is a range of responses regarding how easy/difficult it is to translate user needs into requirements [g], there is a noticeable indication that the translation process is not foolproof [h]. Even if the translation seems easy or routine, if there is disconnect to the original problem the translation has to improve. Explaining why meeting technical requirements can be disconnected from solving the actual problem, the interviewees commented:

Because the people writing the design requirements don't exactly always know what they want yet or need yet. And so they'll make a suggestion, but sometimes 
it's not until you see [a prototype], that you realize, "[...] it would've been nice to have this or would it be nice to have that." That wasn't caught in the initial design, which is why we put a lot of emphasis on iteration of design. Always be in the loop. Don't go too far without checking in, you know, to see if we're still on the right track. Show something very early on in the development so people get a sense of where it's going. Because it's a lot harder to change course further down the track you go. In these early stages it's very fluid, very dynamic, which is when it's the most impressionable by the needs of the person who's asking. (Cube, 28)

So engineers tend to think in terms of features, so to them anything can be solved with additional features, or different features, to make it big [...] but sometimes, to me it always comes down to the user experience. So the use cases. So it's really everything working together to provide that experience that need to, should matter. So the interaction between the different pieces, how the workflow goes, and should be as seamless as possible in my view. (Yellow, 23)

One way that Cube has addressed the translation gap is to acknowledge that one's understanding is not complete, and creating the first prototype that serves as a representation of the translation work that has been performed. Users play a critical role in interpreting the prototype and redefining the problem or design goals. The actual translation is not made explicit; more examples of intermediary representations and designer explanations will be needed.

Yellow highlights another aspect that should be addressed: switching the perspective lens. As Yellow has, an engineer can learn to step outside the e.g. features perspective, to enter the user experience perspective, and re-create the connections. Simply adding features based on the first experience-feature connection, when the understanding of the experience has changed, will not be adequate.

Related to the possible disconnect between technical requirements, design goals and the actual problem phenomena, is the issue of impact evaluation (Fig. 4) [i, j]. It can be reasonably expected that difficulties in inquiry and contextualization may both limit the information, tools, perspective lenses available to define, assess, and explain long-term impact.

i. It is difficult to assess the actual impact of design work on the immediate users.

j. It is difficult to evaluate the impact of design work on the industry, society, environment, and on technology itself.

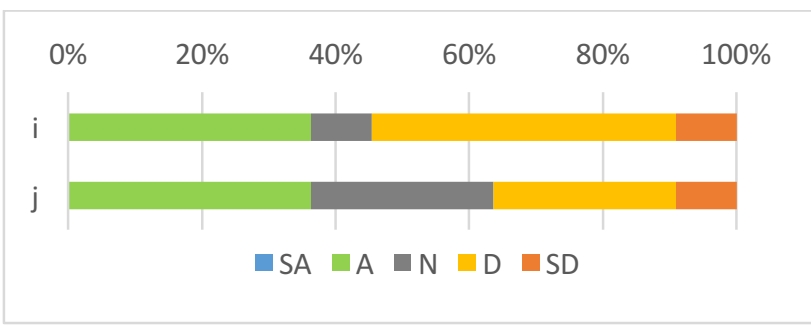

Fig. 4. Survey Responses on Impact Evaluation.

With lack of robust theories or guidelines on how to study and explain the impact of design solutions, often the success of design has to be inferred based on user uptake: "[...] it's expressed by them using it. And it's expressed by them asking for more. [...] They'll use it and then they're more productive. And it was a successful tool" (Cube, 24$25)$. While there is a general sense of success, there is little explanatory power, and thus less specific information about what exactly works and why, what details are transferable across contexts, etc. Without the ability to research using in-depth human data (properly and ethically), organizations can rely on secondary data, collected feedback, and available metrics to define and assess their impact. Developing more robust, effective metrics for impact would require, first of all, a theoretical model of the main phenomenon addressed by the design solution; secondly, additional skills in transforming what is often qualitative into what can be quantitatively measured.

\subsection{Reflective Practice}

k. Engineering design work must be ethical in its process as well as its outcome.

l. I am expected and encouraged to challenge biases and assumptions that cause ethical problems in the design work.

m. I have support and room for autonomy, to exercise creativity in my design project-related work.

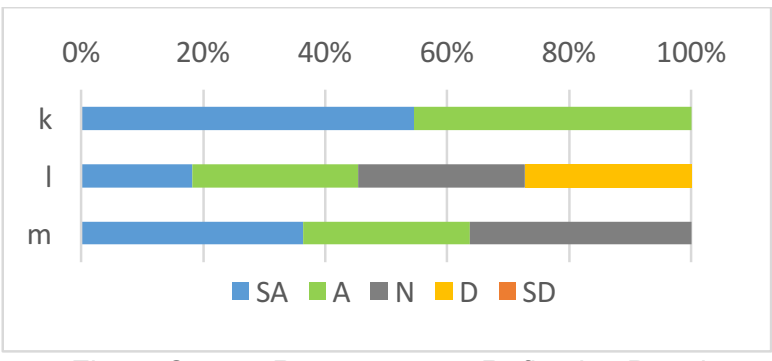

Fig. 5. Survey Responses on Reflective Practice.

Design is an important space for ethical leadership in technology development and impact. The discrepancy between the importance of ethics in engineering design $[\mathrm{k}]$, and the experienced organizational support for 
responsible design practice [1] may raise an important concern. There is a shared space for design education and engineering ethics education, in which attention must be paid to both the engineers as individuals, as well as the organization as an important influencer on engineering ethics (rather than solely dependent on the engineering profession).

Table 1: Selected Open-Ended Questions and Responses from Survey*

Q: Changes needed to improve design quality and positive impact

- More people on corporate boards \& government with understanding of engineering design process (F6)

- Greater representation of engineers in political leadership (F6)

- Mentorship from senior engineers and top management (F2)

- More freedom/flexibility to individuals to determine [co-develop] the final design (M7)

- Embracing new technologies, with appropriate rules $\&$ constraints that are different from conventional (F5)

- Technology stewardship (F6)

- Thinking about the environmental impact and social impact (F5; M2)

- Better communication of impact; Improved visibility of impact with connection to individual project resources (F5; M3)

- Self-directed learning and ongoing training (M4)

- Government incentive (M1)

Q: Important values, perspectives, attitudes for designing complex solutions

- Value of stakeholders; User-centredness, serviceorientation (M6; F5; M2; M1; F2)

- Long-term thinking, continuous learning/evaluation/iteration; high standards (M4; M3; F2)

- Ethics, equity, equality, advances in human development (M4; M2; F6)

- Historical data, new trends and visions; forget BAU (F5; F2)

- Discretion, judging relevance among unknowns (M3)

- Safety and user protection (F5)

- Ownership (M2)

- Constraints-company ability (M1)

- Positive attitude, confidence based on competence (F6; M7)

- Openness to learning and listening (F6; M3)

- Ability to influence (F6)
Q: Suggestions to help facilitate socio-technical knowledge integration

- Shift in organizational policies, to require multidisciplinary integration and better hiring of these skills (M7; M3)

- Broader education, workshops, training, examples, interdisciplinary conferences and industry networks (M4, M1; F2)

- Transdisciplinary voices heard/integrated in the design/development phase (F6; M7; M3)

- Greater communication with others, more dialogue (F5; M4); "Every engineer to have a sociologist as a friend" (F6)

- Greater integration of sustainability metrics and reporting (F6)

- Certification program, similar to fair trade or LEED (F6)

- Reinvent the way we teach engineering (M2)

- Tax credit for company (M1)

* Similar responses were merged together, keeping the in vivo terms as much as possible.

Survey responses to open-ended questions (Table 1) also show that engineers themselves recognize the need to empower individual engineers, as well as increase the integration of engineering responsibilities in the organizational leadership and practices.

The presented questions are a few examples of topics that may be included in one's reflection on the design practice. Participants identified areas of need for knowledge and tools (e.g. metrics), values and content that are important to include in the design practice (e.g. technology stewardship, sustainability), and also possible strategies to help improve practice (e.g. representation in senior leadership, incentives and requirements). These call for further research on engineering design.

\section{CONCLUSION}

Conceptualizing STKI-relevant designer capabilities was useful in prompting engineers' explanations and examples from practice. This helped identify potential key interactions, skills, values, perspectives, outputs and organizational factors that influence STKI needed for project success.

From five separate categories of abilities, particular relationships between them began to emerge. Effective inquiry through direct engagement with stakeholders helped develop a contextualized understanding of the design problem at hand, which would enable the translation of its qualitative aspects into design and evaluation criteria. Organizational culture and workplace arrangements have a strong influence on which key interactions can take place, which in turn affect how 
diverse knowledge can be integrated and which skillsets can be exercised.

One artefact that facilitated feedback and consensusbuilding around the problem knowledge and design priorities, was the first prototype of the design solution. Other communicable evidence of contextualization and translation include: problem statement, design requirements, impact metrics, and the design philosophy of key stakeholders involved. Although not discussed in this paper, negotiation skills were also important in consensus-building amidst competing interests and expectations.

Findings suggest that 'impact evaluation' is a key area where research can make immediate contributions to design practitioners. With limited access to data sources or well-developed metrics, success often has to be inferred without specific details about how and why their work creates desired outcomes. Design engineers want to know how their work was successful and could contribute to ethical and sustainable outcomes. Organizations, including engineering schools, investing into impact evaluation may enhance the long-term view, innovation, and morale of their engineering staff and trainees.

\section{Acknowledgements}

We gratefully acknowledge the financial support by Quanser, National Sciences and Engineering Research Council (NSERC), Queen Elizabeth II Graduate Scholarships in Science \& Technology (QEII-GSST) and Ontario Graduate Scholarships programs.

\section{References}

[1] Michael Gibbons and Helga Nowotny, "The potential of transdisciplinarity," in J. Kleinm, R. Häberli, R. W. Scholz, W. GrossenbacherMansuy, A. Bill, and M. Welti (eds.), Transdisciplinarity: Joint Problem Solving among Science, Technology, and Society (pp. 6780), Basel: Birkhäuser Basel, 2001, 332 pp.

[2] Patric Brandt, Anna Ernst, Fabienne Gralla, Christopher Luederitz, Daniel J. Lang, Jens Newig, Florian Reinert, David J. Abson, and Henrik von Wehrden, "A review of transdisciplinary research in sustainability science," Ecological Econ., vol. 92, pp. 1-15, 2013.

[3] Atila Ertas, Transdisciplinary Engineering Design Process. Hoboken, NJ: John Wiley \& Sons, 2018, 833 pp.

[4] Maurits Ertsen, "The technical and the social in engineering education," in J. Frascara (Ed.), Design and the Social Sciences: Making
Connections (pp. 146-157), New York: Taylor \& Francis, 2002, 256 pp.

[5] Jesper Simonsen, Jørgen Ole Bærenholdt, Monik Büscher, and John Damm Scheuer (eds.), Design Research: Synergies from Interdisciplinary Perspectives, New York: Routledge, 2010, 240 pp.

[6] Kristo Miettinen, "Design: Structure, Process, and Function. A Systems Methodology Perspective," in P. E. Vermaas et al. (Eds.), Philosophy and Design: From Engineering to Architecture (pp. 217-231). Springer, 2008, 360 pp.

[7] Gerhard Fischer, "External and shareable artifacts as opportunities for social creativity in communities of interest," in Proc. $5^{\text {th }}$ International Conf. on Computational and Cognitive Models of Creative Design, J. Gero and L. Maher (eds.) (Sydney, AUS; December 2001), 23 pp., 2001.

[8] Anselm Strauss and Juliet Corbin, Basics of Qualitative Research: Grounded Theory Procedures and Techniques (2nd ed.), Newbury Park, CA: SAGE, 1990, 272 pp. 


\section{APPENDIX A: SURVEY PARTICIPANTS}

Selected information about the survey participants are provided below, in order to help situate their open-ended responses that have been included in this paper.

\section{A.1 Survey Participants}

\begin{tabular}{|c|c|c|c|}
\hline \multirow{4}{*}{$\begin{array}{c}\text { Female } \\
\text { engineers }\end{array}$} & F1 & $\begin{array}{c}\text { Experience in } \\
\text { Eng. Design }\end{array}$ & $\begin{array}{c}\text { Age } \\
\text { Range }\end{array}$ \\
\cline { 2 - 4 } & F2 & 4-6 years & $35-44$ \\
\cline { 2 - 4 } & F3 & 7-14 years & $35-44$ \\
\cline { 2 - 4 } & F4 & 4-6 years & $25-34$ \\
\cline { 2 - 4 } & F5 & 4-6 years & $25-34$ \\
\cline { 2 - 4 } engineers & F6 & 15+ years & $25-34$ \\
\hline \multirow{7}{*}{ Male } & M1 & 7-14 years & $55-64$ \\
\cline { 2 - 4 } & M2 & $1-3$ years & $25-54$ \\
\cline { 2 - 4 } & M3 & $1-3$ years & $25-34$ \\
\cline { 2 - 4 } & M4 & $15+$ years & $55-64$ \\
\cline { 2 - 4 } & M5 & $7-14$ years & $35-44$ \\
\cline { 2 - 4 } & M6 & $7-14$ years & $35-44$ \\
\cline { 2 - 4 } & M7 & $7-14$ years & $35-44$ \\
\hline
\end{tabular}

\section{A.2 Survey Participants: "Have you ever..."}

$\mathrm{A}=$ “... been involved in an engineering design project that required you to learn from disciplines outside your original training?" - Yes/No

$\mathrm{B}=$ " $\ldots$ had to learn knowledge pertaining to humanand social- systems, in order to complete your design work of technical systems?" - Yes/No

$\mathrm{C}=$ “... considered yourself a designer of sociotechnical systems, in which people and technology are integrated into the processes as system components?" Yes/No

$\mathrm{D}=$ “... evaluated the impact of your design solutions on people, community, or organizations?" - Yes/No

\begin{tabular}{|c|c|c|c|c|}
\hline & A & B & C & D \\
\hline F1 & Yes & Yes & Yes & Yes \\
\hline F2 & Yes & Yes & Yes & Yes \\
\hline F4 & Yes & Yes & Yes & Yes \\
\hline F5 & Yes & Yes & Yes & Yes \\
\hline F6 & Yes & No & Yes & Yes \\
\hline M1 & Yes & No & Yes & No \\
\hline M2 & Yes & No & No & Yes \\
\hline M3 & Yes & Yes & Yes & Yes \\
\hline M4 & Yes & Yes & Yes & Yes \\
\hline M6 & Yes & No & No & Yes \\
\hline M7 & Yes & Yes & No & Yes \\
\hline
\end{tabular}

